\title{
Dehydroepiandrosterone improves murine osteoblast growth and bone tissue morphometry via mitogen-activated protein kinase signaling pathway independent of either androgen receptor or estrogen receptor
}

\author{
Ling Wang ${ }^{1}$, Yu-Dong Wang ${ }^{1}$, Wen-Jun Wang ${ }^{1}$, Ying Zhu' ${ }^{1}$ and Da-Jin Li ${ }^{1,2}$ \\ 'Laboratory for Reproductive Immunology, Hospital and Institute of Obstetrics and Gynecology, Fudan University Shanghai Medical College, 413 Zhaozhou Road, \\ Shanghai 200011, China \\ ${ }^{2}$ Department of Obstetrics and Gynecology, Hainan Medical College, The Affiliated Hospital, Haikou 570102, China \\ (Requests for offprints should be addressed to D-J Li; Email: djil@shmu.edu.cn) \\ (Y-D Wang is now at Department of Obstetrics and Gynecology, the Sixth People's Hospital, Shanghai Jiaotong University, Shanghai 200233, China)
}

\begin{abstract}
Dehydroepiandrosterone (DHEA) may be a promising agent for postmenopausal osteoporosis (PMO), but its mechanism to modulate osteoblasts (OBs) is yet to be explained. To elucidate the effects of DHEA treatment on the ovariectomized (OVX) mice and its mechanisms, we evaluated the morphology of mice bone tissue and expression of proliferating cell nuclear antigen (PCNA) in the vertebrae-derived OB after having treated the OVX animals with DHEA. The results showed that DHEA administration increased the expression of PCNA in OB and changed the bone tissue morphometry of the PMO model. To further investigate this mechanism, the OB was isolated from neonatal mice calvariae by the enzymedigested assay, exposed to DHEA, and then analyzed for ultrastructure, DNA content, early apoptotic cells, and phosphorylation of extracellular signal-regulated kinase $1 / 2$. It was found that DHEA promoted proliferation and inhibited apoptosis of $\mathrm{OB}$ significantly, via mitogen-activated protein kinase signaling pathway independent of either androgen receptor or estrogen receptor, suggesting that it may exert roles via a DHEA-specific receptor directly, not by way of conversion to androgens or estrogens.
\end{abstract}

Journal of Molecular Endocrinology (2007) 38, 467-479

\section{Introduction}

Postmenopausal osteoporosis (PMO) is a metabolic bone disease characterized by a decrease in bone mass after menopause. Normal bone remodeling depends upon a balance between the osteoblast (OB)-mediated bone formation and the osteoclast-mediated bone resorption. After surgical or natural menopause, bone resorption exceeds bone formation, which leads to an imbalance in favor of bone resorption and a decrease in bone mass. Skeletal system homeostasis is greatly influenced by endocrine factors (McLachlan et al. 1996, Ben-Nathan et al. 1999, Rho et al. 2004). Up to now, approaches to managing PMO have been directed toward prevention of bone resorption. Estrogen replacement therapy appears to act mainly through inhibition of resorption and has been widely used in postmenopausal women for several years. However, concerning safety, an observational study questions the suitability of long-term estrogen therapy (Enserink 2002). The OB, regulated by the local microenvironment, is a bone-forming cell that regulates bone metabolism, and its dysfunction plays a central role in the pathogenesis of PMO. A number of investigations have demonstrated that regulation of the OB lifespan is critical for the maintenance of the skeleton; so a promising prophylactic and therapeutic regimen to PMO should be administered that stimulates OB bone formation in PMO.

Dehydroepiandrosterone (DHEA) is among the most plentiful circulating adrenal hormones and is one of the most abundant adrenal sex steroid hormone precursors in adult women. It exerts biological activities, not by its metabolites (Yen et al. 1995, Araghi-Niknam et al. 1998, Jiang et al. 1998, Flynn et al. 1999, Zhang et al. 1999). It has been demonstrated that DHEA, as an additional molecule modulating bone mineral density (BMD) in postmenopausal women, emphasizes the need for more information concerning potential clinical benefit for the treatment of PMO (Casson \& Buster 1995, Labrie et al. 1997, Lamberts et al. 1997). However, both the molecular and biochemical mechanisms by which DHEA exerts its roles in bone metabolism remain shrouded in mystery. The steroid receptor for DHEA has not been identified, and DHEA 
is generally considered to exert its roles via conversion to androgens or estrogens (Haning et al. 1991a,b). It has been demonstrated that murine and human $\mathrm{T}$ cells have a specific receptor for DHEA (Meikle et al. 1992, Okabe et al. 1995).

The aim of present study is to elucidate the mechanisms underlying the DHEA-mediated OB lifespan modulation in vivo and in vitro, using $17 \beta$-estradiol (E2) as control. We have examined the morphology of bone tissue in vivo and expression of proliferating cell nuclear antigen (PCNA) in the ex vivo vertebrae-derived OB after having treated the OVX animals with DHEA or E2. In vitro OBs from neonatal murine calvariae were exposed to DHEA or E2, examined for the ultrastructure, DNA content, early apoptosis, and phosphorylation status of extracellular signal-regulated kinase 1/2 (ERK1/2). We used ICI 182780 (ICI) as an estrogen receptor (ER) antagonist, flutamide (FLUT) as an androgen receptor (AR) antagonist, and U0126 as inhibitor of mitogen activated protein kinase (MAPK) pathway to investigate the mechanisms underlying the effects of DHEA on OB.

\section{Materials and methods}

\section{Mice}

Inbred strains of $B A L B / c$ mice (10-12 weeks of age) were obtained from the Jackson Laboratory (Bar Harbour, ME, USA) and subsequently maintained in the Laboratory Animal Facility of the Chinese Academy of Sciences (Shanghai, China). The housing and handling of the experimental animals were performed in accordance with the guidelines of the Chinese Council for Animal Care.

$B A L B / c$ mice were habituated to the housing conditions for 2 days. Mice were housed five per cage on a reversed $12 \mathrm{~h}$ light: $12 \mathrm{~h}$ darkness cycle. Food and water were available ad libitum at room temperature. Mice that were ovariectomized were used as PMO model; newborn $B A L B / c$ mice were used as OBs.

\section{Reagents}

Fetal bovine serum (FBS), minimum essential medium (MEM), and MEM without phenol red were purchased from GIBCO Co. 17 $\beta$-E2, DHEA, U0126, flutamide, alkaline phosphatase (ALP) staining kit, trypsin, and collagenase type 2 were purchased from Sigma-Aldrich Co. ICI 182780 was purchased from Tocris Cookson (Bristol, UK) SDS was obtained from Serva Co. (Heidelberg, Germany) ACTIVE DHEA enzyme immunoassay (EIA) kit was purchased from Diagnostic System Laboratories (DSL, Webster, TX, USA). DHEA sulfate (DHEAS) EIA kit was supplied by IBL. E2 EIA kit was supplied by BioCheck Inc (Burlingame, CA, USA).
Fluorescein isothyocyanate (FITC) - conjugated antiPCNA antibody (IgG2a) was purchased from eBioscience (San Diego, CA, USA). Cycle TEST \& DNA Reagent Kit was obtained from BD Biosciences (San Jose, CA, USA) Annexin V-FITC was supplied by Bender Med Systems (Vienna, Austria). Monoclonal antibody against phospho-pERK1/2 MAPK (Thr202/Tyr204) and rabbit polyclonal antibody against pERK1/2 MAP kinase were purchased from Cell Signaling Technology Inc. (Beverly, MA, USA) and the secondary antibody conjugated with horseradish peroxidase was from Rockland Co (Gilbertsville, PA, USA).

\section{Experimental protocols in vivo}

Four groups of mice were studied using the following protocols. The animals were anesthetized with ether. Ovariectomy was performed through bilateral incisions. Sham group underwent the surgical procedure but without ovariectomy, and 1 week after surgical procedure the mice were treated daily with saline containing $0 \cdot 1 \%$ ethanol. One week after gonadectomy, the mice were divided into three groups $(n=12)$. Ovariectomy (OVX) group was subjected to ovariectomy at the beginning of the experiment and treated with saline containing $0 \cdot 1 \%$ ethanol daily. Estrogen replacement treatment $(\mathrm{OVX}+\mathrm{E} 2)$ group was subjected to ovariectomy at the beginning of the experiment and received E2 treatment $(100 \mu \mathrm{g} / \mathrm{kg}$ per day orally). DHEA treatment (OVX+DHEA) group was subjected to ovariectomy at the beginning of the experiment and received DHEA treatment ( $5 \mathrm{mg} / \mathrm{kg}$ per day orally). All four groups received equal quantities of fluid at the same time during treatment. All mice were intragastricly administrated daily for 90 consecutive days at 8 a.m.

All mice were killed after 3 months treatment; blood was collected from the hearts, and serum was stored at $-20^{\circ} \mathrm{C}$ for the determination of DHEA, DHEAS, and E2, which was performed using the EIA kits (data not shown).

\section{Bone histomorphometry}

Femur and lumbar vertebrae were removed at the time of necropsy, cleaned of soft tissue and fixed in $4 \%$ paraformaldehyde in PBS for $\sim 12 \mathrm{~h}$ at $4{ }^{\circ} \mathrm{C}$. The specimens were then decalcified in $0.5 \mathrm{M}$ EDTA in PBS (pH 7.4) and dehydrated with increasing concentrations of ethanol before being embedded in paraffin. The specimens were sectioned at $6 \mu \mathrm{m}$ and hematoxylin-eosin stained using standard techniques. Bone histomorphometry was performed in a blinded manner, by a board-certified veterinary pathologist. A histomorphometric analysis of the trabecular bone was performed using a Nikon microscope and digitizers equipped with a computerized semi-automatic image 
analysis system (Cosmozone II; Nikon, Tokyo, Japan), as described previously (Zhioua et al. 1994, Thomsen et al. 2000, Morony et al. 2001, Kostenuik et al. 2004, Elefteriou et al. 2005). Six to nine fields were measured per section. We obtained the trabecular bone volume/ total volume (BV/TV[B.Ar/T.Ar]) by counting the number of pixels representing the bone and marrow phases respectively. The number of pixels representing the bone area was divided by the sum of the number of pixels representing the bone and marrow area. The bone area (B.Ar), marrow area (Ma.Ar), and tissue area (T.Ar) could then all be computed.

\section{Flow cytometry (FCM) analysis of PCNA in OB}

Murine OBs were isolated from vertebrae using a technique as described previously (Granchi et al. 2004). Briefly, lumbar vertebrae (LV1-LV4) were obtained at the time of necropsy; trabecular bone was dissected into tiny fragments, washed twice with PBS, and incubated in MEM supplemented with 20\% FBS and antibiotics. The bone fragments were fed regularly and left until many cells had spread out from the fragments to semi-confluent layer, OBs were characterized by the measurement of biochemical and cytochemical ALP with nitroblue tetrazolium salt/5 bromo-4-chloro-3-indolylphosphate (NBT/BCIP). The cells were $>95 \%$ homogeneous and displayed a mature (normal) osteoblastic phenotype.

When OBs reached confluence, they were detached using trypsin; the cells were then passaged and maintained until use. The primary OBs were seeded onto 24-well flat-bottomed culture plates at a density of approximately $1 \times 10^{5}$ cells $/ \mathrm{cm}^{2}$. Within $24 \mathrm{~h}$, the supernatant was removed and the fresh medium containing 20\% FBS was added. This cell analysis requires the establishment of culture conditions that permit the rapid expansion of these cells while retaining their potential for further differentiation. Several culture models have been proposed, using fetal calf serum (FCS) as a source of growth factors (Schecroun \& Delloye 2004). Within $24 \mathrm{~h}$ of culture, the cells were harvested and resuspended in PBS at a density of $5 \times 10^{6} / \mathrm{ml}$ and then distributed (100 $\mu \mathrm{l}$ per tube) to the Falcon 2054 polystyrene round-bottomed tubes (Becton Dickinson) for immunolabeling. The cells were fixed, permeabilized, and stained for PCNA using FITC-labeled antibodies. Thereafter, the cells were washed twice and resuspended in PBS for FCM analysis. The samples were analyzed in a FACS Calibur flow cytometer (Becton Dickinson, Palo Alto, CA, USA) using Cellquest software (Becton Dickinson). Statistical analysis was done using isotype-matched controls as a reference. The experiments were repeated five times.
Osteoblastic cell isolation by enzymatic digestion and culture

Murine osteoblastic cells were isolated from calvariae of neonatal $B A L B / c$ littermates by enzymatic digestion as described previously (Robey \& Termine 1985, Inoue et al. 1999). In brief, aseptically removed frontal and parietal bones were digested with the enzyme mixture $(0.1 \%$ collagenase type $2,0.05 \%$ trypsin, and $0.5 \mathrm{mM}$ EDTA). The osteoblastic cells released were collected and seeded onto a $60 \mathrm{~mm}$ dish in MEM supplemented with $10 \%$ FBS. Half million OBs at the second passage were cultured in $25 \mathrm{~cm}^{2}$ culture flask or seeded onto a 24-well plate and cultured at $37^{\circ} \mathrm{C}$ in $95 \%$ humidified air plus $5 \% \mathrm{CO}_{2}$. The osteoblastic phenotype derived from calvariae was confirmed by staining for the presence of ALP with NBT/BCIP. The cells were > 95\% homogeneous and displayed a mature osteoblastic phenotype. The cell density was similar in all samples. The OBs were grown in MEM without phenol red, and supplemented with the 5\% charcoal-dextran-treated FCS (5\% CD-FCS) for at least 4 days before the start of DHEA or E2 treatment.

\section{The primary OBs were treated in vitro with DHEA or E2}

The OBs were grown in 5\% CD-FCS MEM medium without phenol red for at least 4 days until $70-80 \%$ confluence $\left(2 \times 10^{5}\right.$ cells $/ \mathrm{cm}^{2}, 24$-well plates $)$. After deprivation of serum for a further 12-24 h, the OBs were pretreated with the solvent control, $1 \mu \mathrm{M}$ ICI $182780,10 \mu \mathrm{M}$ flutamide, or $100 \mu \mathrm{M} \mathrm{U} 0126$ for $1 \mathrm{~h}$, and then treated with $10^{-5}-10^{-10} \mathrm{M}$ DHEA, $10^{-9}-10^{-10} \mathrm{M}$ $\mathrm{E} 2$, or the solvent control for $72 \mathrm{~h}$ in serum-free medium.

\section{Transmission electron microscopy (TEM)}

The primary OBs were cultured until approximately $80 \%$ confluent and then treated with $10^{-7} \mathrm{M}$ DHEA or the solvent control for $72 \mathrm{~h}$. After washing with PBS, the OBs were fixed in $2.5 \%$ glutaraldehyde postfixed in $1 \%$ osmium tetroxide. They were rinsed with water, dehydrated, and embedded in epoxy resin. Ultrathin sections $(70-90 \mathrm{~nm})$ were cut and stained with $2 \%$ uranyl acetate and Reynold's lead citrate for TEM observation with a JEM-1200 EX microscope (JOEL Co., Tokyo, Japan). Ten fields were randomly chosen at each section and the images were stored, and morphological quantitative analysis was performed using a computerimaging analysis system. Estimations of ER area per unit volume of $\mathrm{OB}$ cytoplasm were performed according to the method described previously (Itani et al. 1992). The mitochondrial density was calculated as the ratio of the total area of all mitochondria to the entire area of the OB cytoplasm (Mei et al. 1999). 


\section{FCM for cell cycle of OBs}

For the determination of the cell cycle progression, the cells were harvested and washed with PBS, and then incubated in $70 \%$ ethanol for at least $12 \mathrm{~h}$ at $4^{\circ} \mathrm{C}$. The fixed and permeabilized cells were collected by centrifugation, washed with PBS, stained with propidium iodide $(10 \mu \mathrm{g} / \mathrm{ml})$, and analyzed with FACS. The percentage of the cells in the $\mathrm{G} 0 / \mathrm{G} 1, \mathrm{~S}, \mathrm{G} 2 / \mathrm{M}$ phases, and proliferation index $(\mathrm{PI}, \mathrm{PI}=(\mathrm{S}+\mathrm{G} 2 / \mathrm{M}) /(\mathrm{G} 0 / \mathrm{G} 1+\mathrm{S}+\mathrm{G} 2 / \mathrm{M}) 100 \%)$ were evaluated.

\section{Apoptosis analysis by FCM}

After incubation for $72 \mathrm{~h}$, the OBs were released from the culture dish using trypsin-EDTA, resuspended in the medium, and collected by centrifugation. The cells were washed with PBS, and the apoptotic cells stained with Annexin V-FITC/PI dual-labeling technique and analyzed by FCM. The quantity of Annexin $\mathrm{V}-F I T C^{+} / \mathrm{PI}^{-}$cells corresponded to early apoptosis, while that of Annexin V-FITC ${ }^{+} / \mathrm{PI}^{+}$cells corresponded to late apoptosis or secondary necrosis. In every sample, $1 \times 10^{5}$ cells were counted. The experiment was repeated five times.

\section{Western blot for phosphor-ERK1/2 vs total ERK1/2 in OB}

Western blot was carried out to evaluate protein levels of phosphor-ERK1 $/ 2$ and total ERK1 $/ 2$ in the OBs. The OBs were lysed in 1\% NP-40, $50 \mathrm{mM}$ Tris-HCl (pH 8.0), $150 \mathrm{mM} \mathrm{NaCl}, 100 \mu \mathrm{g} / \mathrm{ml}$ phenylmethanesulfonyl fluoride (PMSF), $1 \mu \mathrm{g} / \mathrm{ml}$ aprotinin, and $0 \cdot 1 \%$ SDS for $30 \mathrm{~min}$ at $4{ }^{\circ} \mathrm{C}$. Nuclei were removed by centrifugation at $12000 \mathrm{~g}$ at $4^{\circ} \mathrm{C}$ for $15 \mathrm{~min}$, and cell lysates were assayed for protein contents using the Bradford protein assay. The proteins $(50 \mu \mathrm{g})$ were resuspended in sample buffer (2\% SDS, $62 \cdot 5 \mathrm{mM}$ Tris, $\mathrm{pH} 6 \cdot 8,0 \cdot 1 \%$ bromophenol blue, $2.5 \%$ 2-mercaptoethanol, and $10 \%$ glycerol), separated on $10 \%$ SDS-polyacrylamide gel. The proteins were electrotransferred to a polyvinylidene difluoride membrane for $1.5 \mathrm{~h}$. The membrane was blocked with $5 \%$ non-fat milk in TBS-T (150 mM NaCl, $20 \mathrm{mM}$ Tris, $\mathrm{pH} \mathrm{7•4,}$ and $0 \cdot 1 \%$ Tween 20) and then incubated with antiphospho-ERK1/2 (1:1000) or anti-ERK1/2 (total; 1:1000) antibodies overnight at $4{ }^{\circ} \mathrm{C}$, followed by incubation with secondary horseradish peroxidaseconjugated antibody (1:2000) for $1 \mathrm{~h}$ at $37^{\circ} \mathrm{C}$. The membrane was developed using dimethylaminoazobenzene according to the manufacturer's recommendations. Data were presented as a ratio of phosphorERK1/2 vs total ERK1/2 (Fitzpatrick et al. 2002).

\section{Statistical analysis}

All values were expressed as the mean \pm s.E.M. Data were analyzed with the aid of SPSS database, and variance was evaluated by one-way ANOVA. Differences were accepted as significant at $P<0 \cdot 05$.

\section{Results}

\section{Effects in vivo of DHEA administration on bone morphology and proliferation of $O B$}

\section{DHEA reversed bone volume loss in OVX mouse model}

The vertebrae and femur cancellous (BV/TV) of the OVX mice without DHEA treatment were significantly lower than that of the sham-operated mice $(P<0 \cdot 01$, Fig. 1). After 3 months of administration, OVX mice treated with DHEA or E2 appeared to have an increased trabecular bone volume of vertebrae and femur compared with that of OVX mice given vehicle $(P<0 \cdot 01$, Fig. 1), which suggests that DHEA treatment can change the bone tissue morphometry of the PMO model.

\section{DHEA increased expression of PCNA in the vertebrae- derived $O B$}

The flow cytometric analysis showed that the average fluorescence intensity $(5 \cdot 676 \pm 0 \cdot 562)$ and positive cell percentage $(3 \cdot 232 \pm 0 \cdot 852)$ of PCNA in the vertebraederived $\mathrm{OB}$ of OVX group increased significantly compared with that of the sham group $(4 \cdot 85 \pm 0 \cdot 401$, $2 \cdot 264 \pm 0 \cdot 219, P<0 \cdot 05)$. Compared with the OVX group, the average fluorescence intensity $(6 \cdot 97 \pm$ $0 \cdot 784$ ) and positive cell percentage $(5 \cdot 712 \pm 0 \cdot 704)$ of PCNA in OB of the OVX group after treatment with DHEA increased significantly $(P<0 \cdot 05, P<0 \cdot 01)$, suggesting that DHEA treatment could promote proliferation of $\mathrm{OB}$. The average fluorescence intensity and positive cell percentage of PCNA in OB also tended to increase in OVX mice treated with E2, but the difference did not achieve statistical significance $(P>0 \cdot 05$, Fig. 2). Moreover, we examined the effect of DHEA administration on mineralized nodule formation of the primary cultured $\mathrm{OB}$ and found that this formation is remarkably improved (data not shown). Therefore, we propose that DHEA administration may promote the proliferation of $\mathrm{OB}$.

\section{Effects in vitro of DHEA on OB growth}

\section{TEM analysis of ultrastructure in OBs}

Within $24 \mathrm{~h}$ of culture, the expression of ALP with $\mathrm{NBT} / \mathrm{BCIP}$ was characterized in murine osteoblastic cells isolated from calvariae of neonatal $B A L B / c$ littermates by enzymatic digestion. The isolated cells were then stained for ALP. Generally, these cells had 

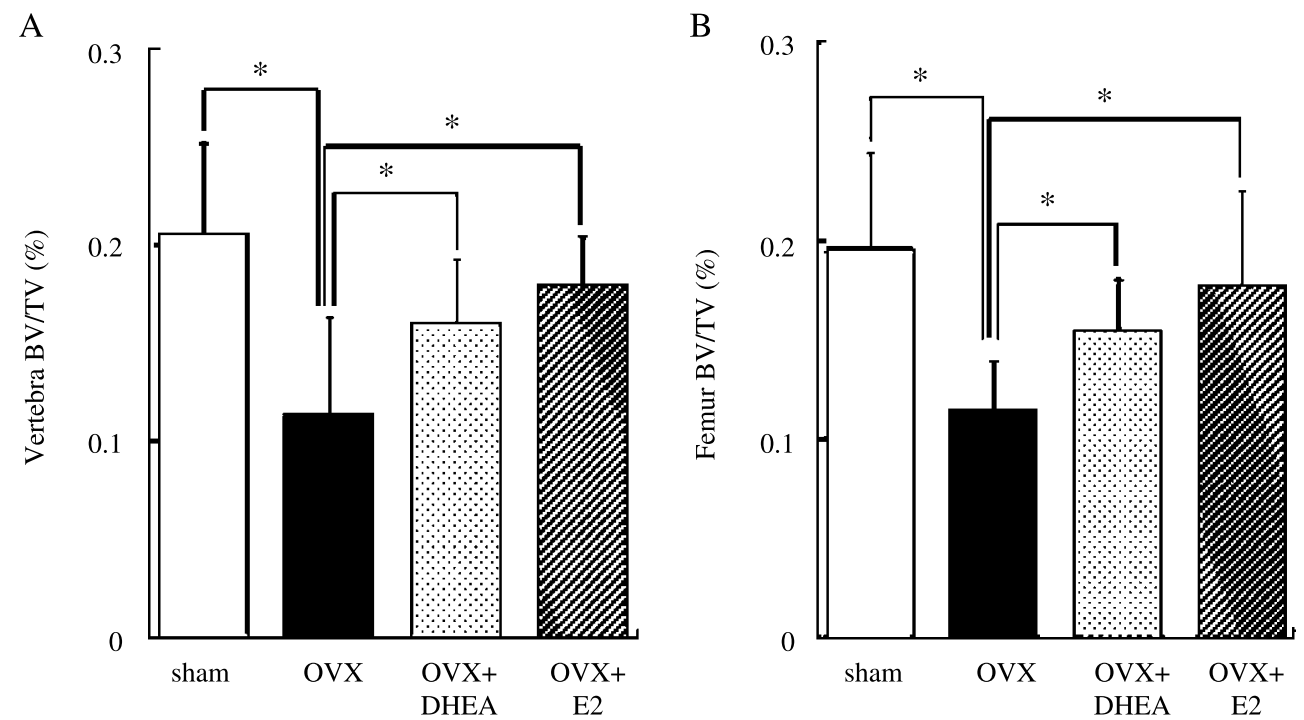

Figure 1 Effects of DHEA on bone histomorphometry of vertebra and femur in OVX mouse. One week after operation, Sham group mice were treated daily with saline containing $0.1 \%$ ethanol. One week after gonadectomy, the mice were divided into 3 groups $(n=12)$. OVX group were treated with saline containing $0 \cdot 1 \%$ ethanol daily. Estrogen replacement treatment (OVX+E2) group received E2 treatment $(100 \mu \mathrm{g} / \mathrm{kg}$ per day orally). DHEA treatment group (OVX + DHEA) received DHEA treatment $(5 \mathrm{mg} / \mathrm{kg}$ per day orally). OVX and sham mice were treated with either vehicle, DHEA $\left(10^{-7} \mathrm{M}\right)$, or E2 $\left(10^{-7} \mathrm{M}\right)$. These mice were necropsied in 3 months, and histomorphometry was performed on cancellous bone in the lumbar vertebrae (A) and proximal femur metaphysis (B). The cancellous bone volume was determined as a percentage of the total bone tissue (bone volume/total volume, BV/TV). Data are expressed as means \pm s.E.M. $(n=5$ mice/group). ${ }^{\star} P<0 \cdot 01$.
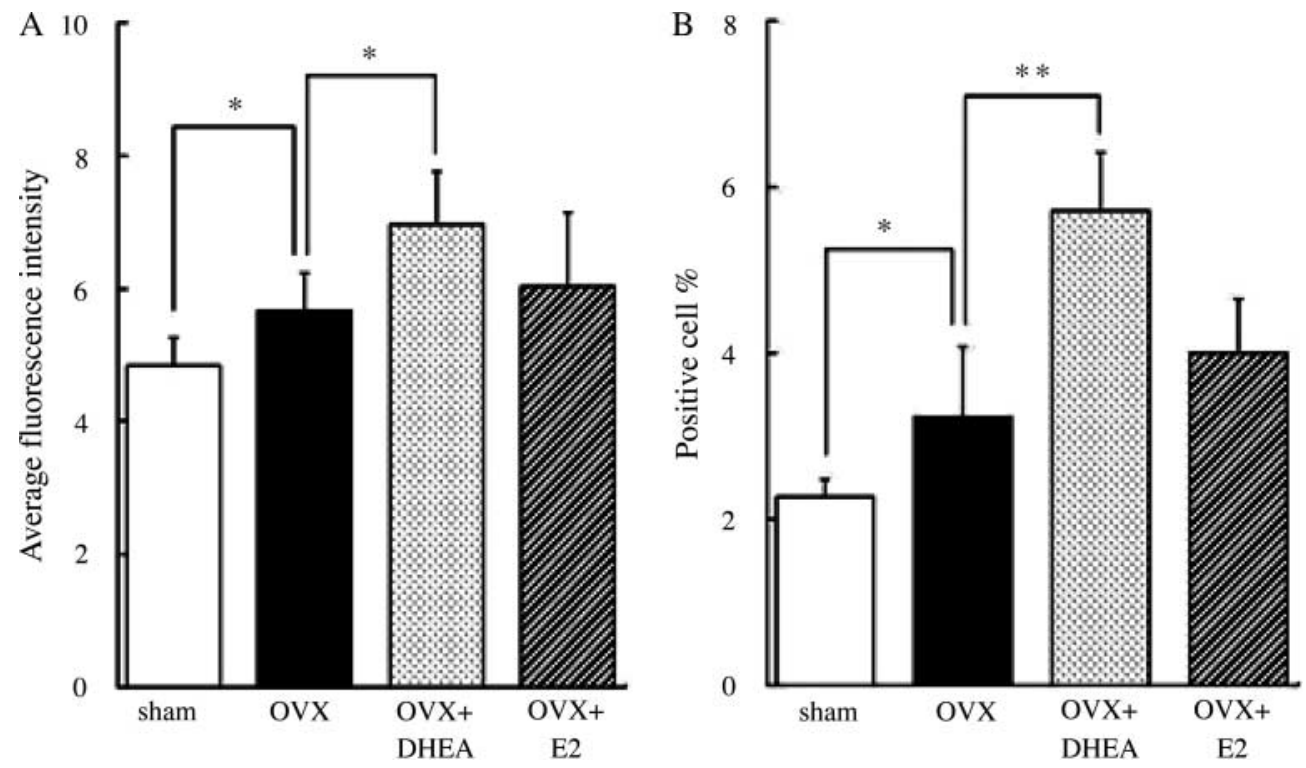

Figure 2 Modulation of DHEA on PCNA expression in OBs. One week after operation, the OVX and sham mice were treated with either vehicle, DHEA $\left(10^{-7} \mathrm{M} ; 5 \mathrm{mg} / \mathrm{kg} / \mathrm{day}\right)$, or E2 $\left(10^{-7} \mathrm{M} ; 100 \mu \mathrm{g} / \mathrm{kg} / \mathrm{day}\right)$. Mice were necropsied 3 months after the treatment, and the OBs isolated from vertebrae were analyzed by flow cytometry for the average fluorescence intensity $(A)$ and positive cell percentage $(B)$ of PCNA. The results shown were from five separate experiments. Data are expressed as means \pm S.E.M. ${ }^{\star} P<0 \cdot 05$, ${ }^{\star *} P<0 \cdot 01$. 


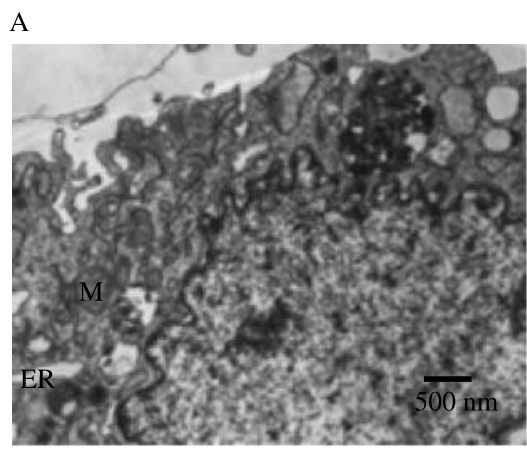

B

Figure 3 The ultrastructure of OBs after treatment with DHEA $(\times 10000)$. Primary OBs were cultured until approximately $80 \%$ confluent, and then treated with solvent (A) or $10^{-7} \mathrm{M} \mathrm{DHEA} \mathrm{(B)} \mathrm{for} 72 \mathrm{~h}$, and the ultrastructure of OBs was observed by TEM. The OBs induced by DHEA showed more organelles, expanded endoplasmic reticulum (ER), and abundant mitochondria (M) compared with the control. (Bars $=500 \mathrm{~nm}$ ).

diverse appearance, every cell appeared to have three to four synapses, which may connect each other, with cytoplasm staining positive for ALP, containing one or two nucleoli; no nuclear staining was observed. The purity of the isolated OBs was above $95 \%$.

After the OBs were treated in vitro with $10^{-7} \mathrm{M}$ DHEA or solvent for $72 \mathrm{~h}$, the ultrastructure of OBs was evaluated by TEM. The results showed that the OBs had organelles of active cells (numerous rough endoplasmic reticulum and well-developed mitochondria; nuclei were large with one or two nucleoli; Fig. 3A); the OBs treated with DHEA were found to have more organelles, expanded endoplasmic reticulum, and abundant mitochondria compared with the control (Fig. 3B). Endoplasmic reticulum area per unit cytoplasmic volume $\left(3 \cdot 128 \pm 0 \cdot 852 \mu \mathrm{m}^{2} / \mu^{3}{ }^{3}\right)$ in OB treated with DHEA increased significantly compared with the control $\left(0 \cdot 385 \pm 0 \cdot 201 \mu \mathrm{m}^{2} / \mu \mathrm{m}^{3}, P<0 \cdot 01\right)$. The augmentation of ER area in OB after DHEA treatment suggests an increase in the protein synthesis of $\mathrm{OB}$. In addition, the mitochondrial density in $\mathrm{OB}$ increased significantly in the DHEA group $(0 \cdot 785 \pm 0 \cdot 351 \%)$ compared with the control $(0 \cdot 328 \pm 0 \cdot 102 \%, P<0 \cdot 01)$. The increase in mitochondrial density in OB after DHEA administration suggests improvement in the energy metabolism of $\mathrm{OB}$.

\section{Modulation of DHEA on cell cycle of the primary $O B$}

To determine modulation of DHEA on cell cycle of OB, the DHEA-treated OBs were evaluated for the percentage of $\mathrm{G} 0 / \mathrm{G} 1, \mathrm{~S}$, and $\mathrm{G} 2 / \mathrm{M}$ phases by FCM. It was shown in Fig. 4 that $10^{-7}$ and $10^{-8} \mathrm{~mol} / 1$ DHEA increased the S-phase $(P<0 \cdot 01)$ and $\mathrm{G}_{2} / \mathrm{M}$ phase $(P<0 \cdot 01)$, decreased the $\mathrm{G}_{0} / \mathrm{G}_{1}$ phase $(P<0 \cdot 01)$ of OBs, and improved the PI significantly $(P<0 \cdot 01)$, while E2 had no effect on PI of OB compared with the control $(P>0.05)$. Moreover, there was no significant difference in the percentage of G0/G1, S, G2/M phases, and PI between the DHEAtreated OB pretreated with and without ICI 182780 (antagonist of estrogen receptor) and flutamide (antagonist of androgen receptor). The promoting effect of DHEA on cell cycle of the primary OB was neither blocked by the estrogen receptor antagonist, ICI 182 780, nor by the androgen receptor antagonist, flutamide, but could be blocked by the specific inhibitor of MAPK pathway, U0126.

\section{Modulation of DHEA on the early apoptosis of the primary $O B$}

In order to investigate the inhibiting effects in vitro of DHEA on the OB apoptosis, we analyzed the percentage of the early apoptotic cells by FCM with the Annexin V-FITC/PI dual-labeling technique and found that $10^{-6}-10^{-9} \mathrm{M}$ DHEA and $10^{-9}-10^{-10} \mathrm{M} \mathrm{E}$ 2 were all capable of inhibiting the serum deprivationinduced early apoptosis of $\mathrm{OB}(P<0.05, P<0.01$ respectively). Moreover, similar to the proliferation promoting effect, the inhibiting effect of DHEA was neither blocked by the estrogen receptor antagonist nor by the androgen receptor antagonist, but could be blocked by the specific inhibitor of MAPK pathway, U0126 (Fig. 5A). Differently, the inhibiting effect of E2 on the OB apoptosis could be blocked by both ICI 182780 and U0126, but not by flutamide (Fig. 5B).

\section{DHEA improved OB growth via activation of MAPK signal pathway}

To probe into the intracellular signal pathway mediating the OBs proliferation/apoptosis by DHEA, the activation of mitogen-activated protein kinases (MAPKs), which convert extracellular stimuli to intracellular signals that control gene expression, cell growth, differentiation, survival, proliferation, and apoptosis was investigated. The cell cycle and apoptosis analysis showed that U0126 completely inhibited the up-regulated proliferation and the down-regulated apoptosis in OBs induced by DHEA 

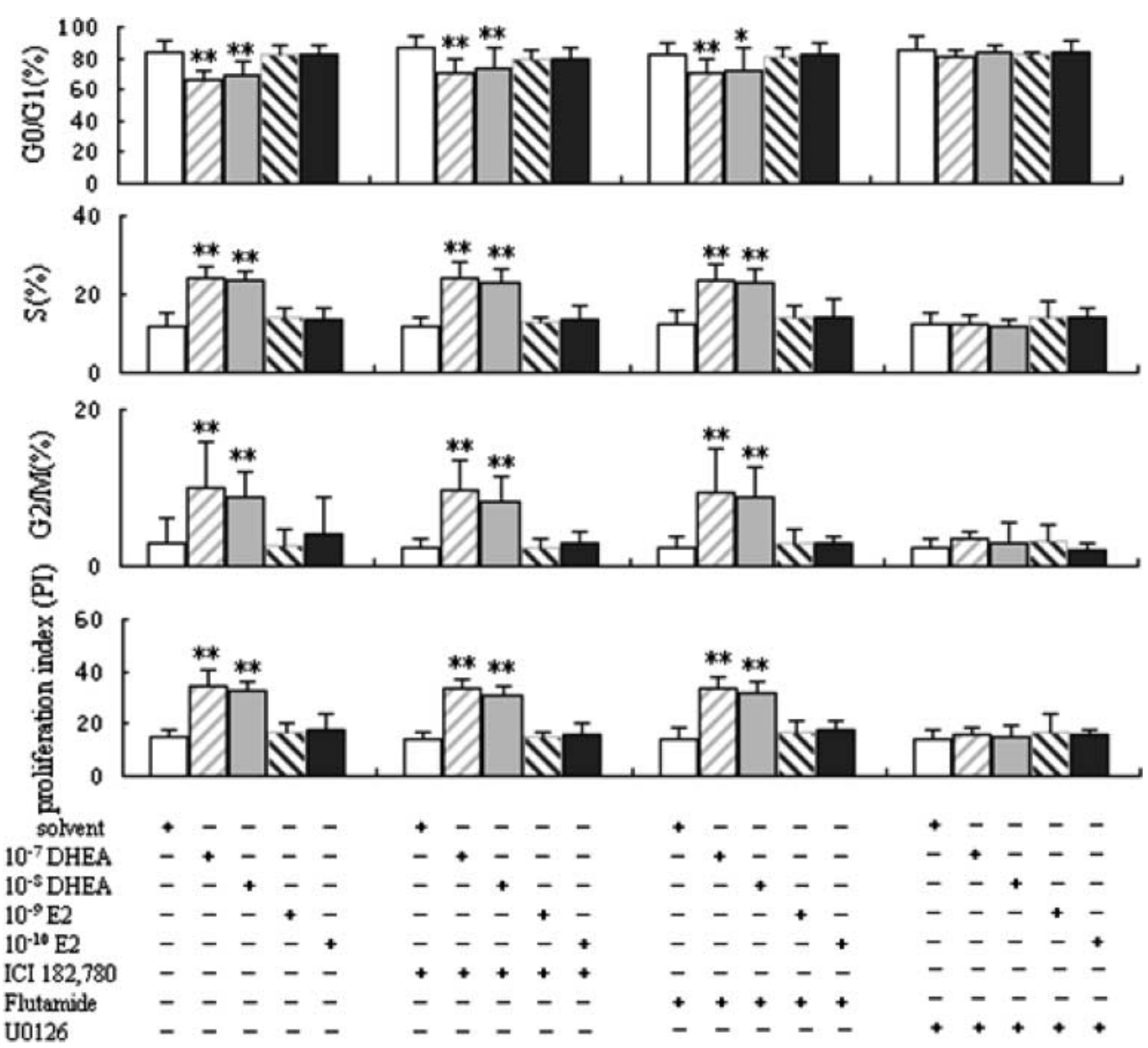

Figure 4 Effect of DHEA on cell cycle of primary OB. The primary OB were grown in $5 \%$ CD-FCS MEM medium without phenol red for at least 4 days until $70-80 \%$ confluent. After deprivation of serum for a further $12 \mathrm{~h}$, the OBs were pretreated with solvent, $1 \mu \mathrm{M} \mathrm{ICI} 182780,10 \mu \mathrm{M}$ flutamide, or $100 \mu \mathrm{M}$ U0126. Then the OBs were incubated for $72 \mathrm{~h}$ in serum-free medium containing DHEA or E2 at the concentrations indicated. The cells were released by trypsin-EDTA, and the cell cycle of OBs was analyzed by FCM with the propidium iodide $(10 \mu \mathrm{g} / \mathrm{ml})$ labeling technique. The percentage of the cells in the G0/G1, S, and G2/M phases were determined. The results are expressed as a percentage of total cells (mean \pm S.E.M.; $n=5$ ). ${ }^{\star} P<0.05 ;{ }^{* \star} P<0.01$ compared with the control.

(Figs 4 and 5). Recent evidence indicates that DHEA administration results in rapid phosphorylation of ERK in endothelial cells (Simoncini et al. 2003). Therefore, we wondered what the action of DHEA or E2 was on the modulation of ERK activation in OB. We analyzed ERK1/ 2 activation in OBs treated with DHEA or E2 by western blot. As shown in Fig. 6A, a significant increase in the rapid phosphorylation of ERKs was observed in OBs after $10^{-7}-10^{-8} \mathrm{M}$ DHEA treatment, showing that DHEA activates the Raf/MEK1/2/ERK1/2 kinase module in OB. To assess further the involvement of the ERK signaling pathway of DHEA in OB, pharmacological agents U0126 (which inhibits ERK), ICI 182780 (ER antagonists), and flutamide (AR antagonists) were used. Phosphorylation of ERK was blocked efficiently by the specific inhibitor of MAPK pathway, U0126; neither ICI 182780 nor flutamide could block this effect of DHEA (Fig. 6B). Moreover, although $10^{-9}-10^{-10} \mathrm{M} \mathrm{E} 2$ were capable of inducing ERK phosphorylation in OBs, the effects of E2 on the ERK phosphorylation of the OBs was not blocked by flutamide, but was blocked by both ICI 182780 and U0126 (Fig. 6C).

\section{Discussion}

Skeletal system homeostasis is greatly influenced by endocrine systems (McLachlan et al. 1996, Ben-Nathan et al. 1999, Rho et al. 2004). PMO has been known to be associated with a variety of endocrine alterations. Recent research presented an association between these pathogenetic changes and disturbances of the endocrine system. DHEA is among the most plentiful circulating adrenal hormones. For many years, scientists assumed that DHEA merely functioned as an inert precursor of the sex steroids, E2 and testosterone. However, following the 

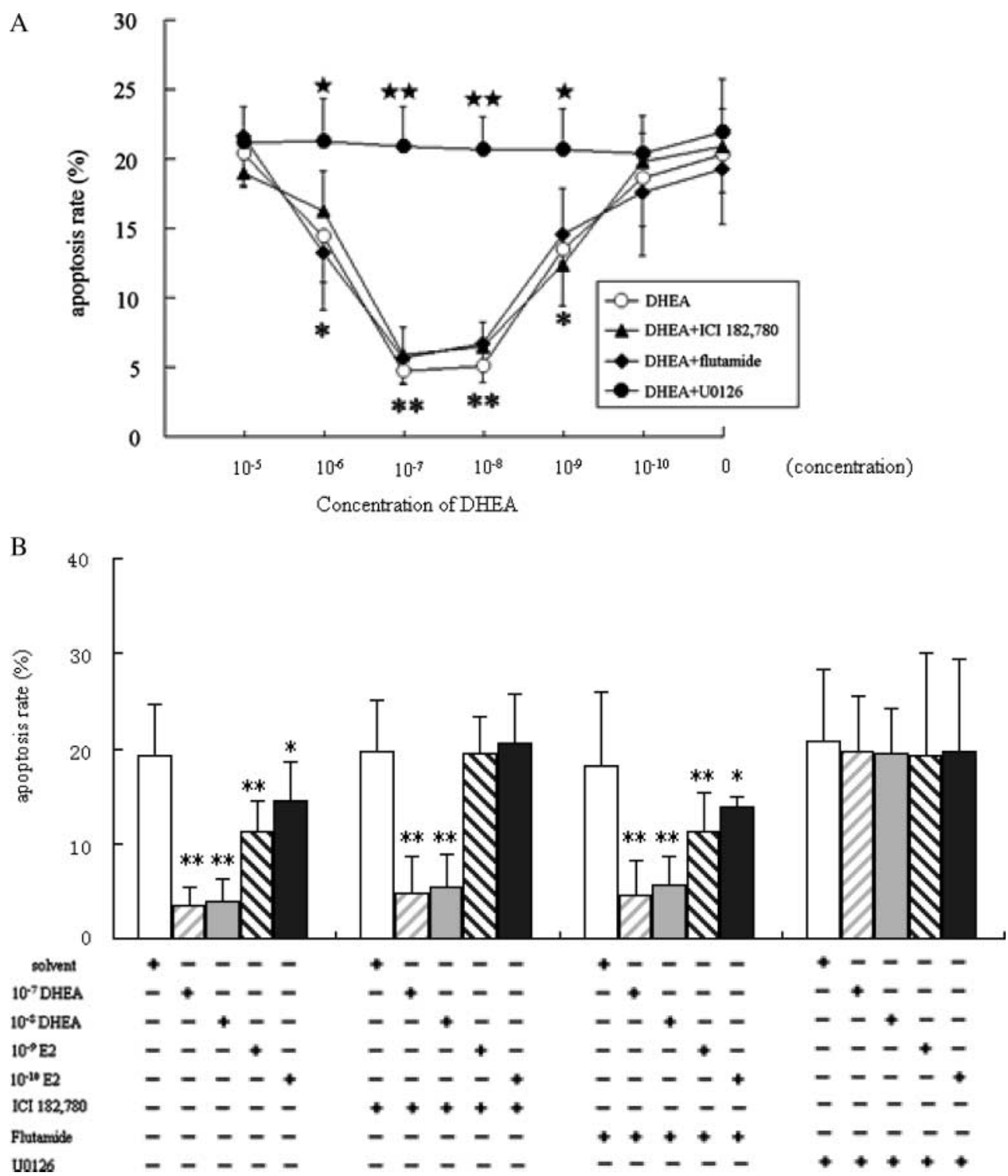

Figure 5 Effect of DHEA on the early apoptosis of primary OBs. The calvariae OBs were allowed to adhere and grow for $24 \mathrm{~h}$ in 5\% CD-FCS MEM medium without phenol red, and then deprived of serum for a further $24 \mathrm{~h}$ (serum-free medium). The OBs were pretreated with solvent, $1 \mu \mathrm{M} \mathrm{ICI} 182780,10 \mu \mathrm{M}$ flutamide, or $100 \mu \mathrm{M} \cup 0126$, and then treated with solvent, DHEA, or E2 at the concentrations indicated in the serum-free medium. After incubation for $72 \mathrm{~h}$, the cells were released by trypsin-EDTA, and the apoptotic cells were stained with Annexin V-FITC/PI dual-labeling technique and analyzed by FCM. The results are expressed as a percentage of total cells (mean \pm s.E.M.; $n=5$ ). ${ }^{\star} P<0.05 ;{ }^{\star \star} P<0.01$ compared with the control; $\square P<0.05$; $\square \square P<0.01$ compared with the other groups.

work of Kalimi and Regelson, the identification of DHEA receptors in the liver, kidney and testes of rats suggests that DHEA has specific physiological actions via its own receptor (Kalimi \& Regelson 1988). Since then, a series of studies has shown that DHEA indeed has a variety of physiological effects, for example, normalizing blood sugar (Bates et al. 1995) and anticarcinogenic (Nyce et al. 1984, Schwartz et al. 1988). Moreover, it has beneficial effects on atherosclerosis (Gordon et al. 1988), dementia
(Flood \& Roberts 1988), and neoplasia (Schwartz \& Pashko 1993).

Although DHEA has been found to present many different effects on various types of cells, tissues, and organs, its concentration in serum declines in a striking age-related fashion in humans (Hakkinen \& Pakarinen 1993, Short \& Nair 1999, Kostka et al. 2000, Miller 2001), which may be strongly associated with multiple age-related clinical disease including PMO. 
A
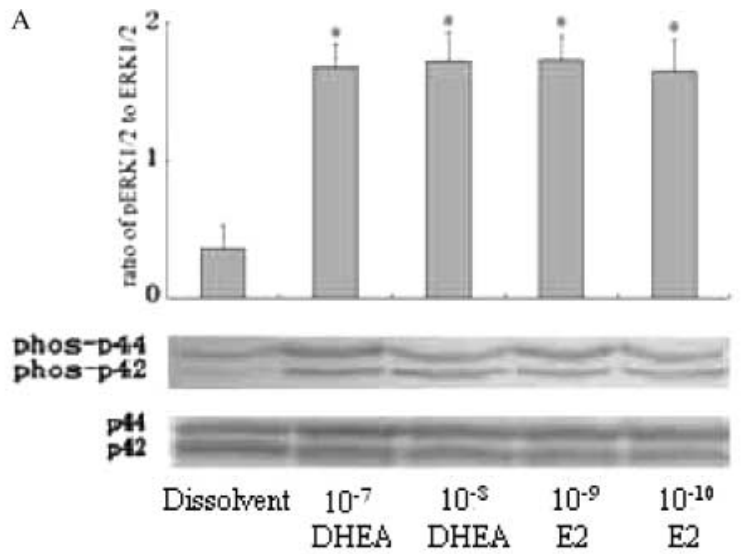

B

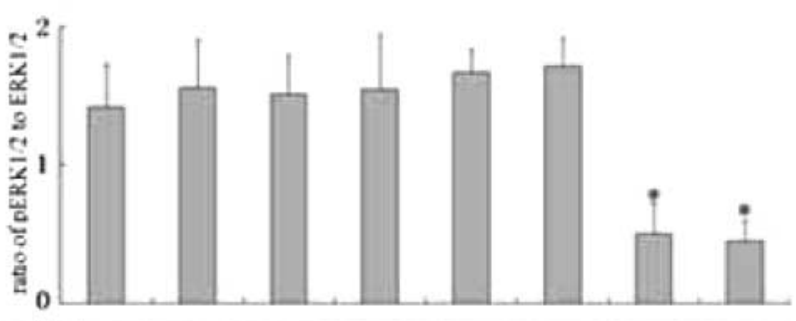

phos-D44

phos-p42

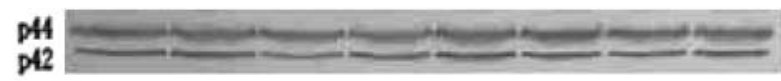

$\begin{array}{lcccccccc}\text { DHEA (M) } & 10^{-7} & 10^{-8} & 10^{-7} & 10^{-8} & 10^{.7} & 10^{.8} & 10^{\circ 7} & 10^{.8} \\ \text { ICI 182,780 } & + & + & - & - & - & - & - & - \\ \text { flutamide } & - & - & + & + & - & - & - & - \\ \text { U0126 } & - & - & - & - & - & - & + & +\end{array}$

C
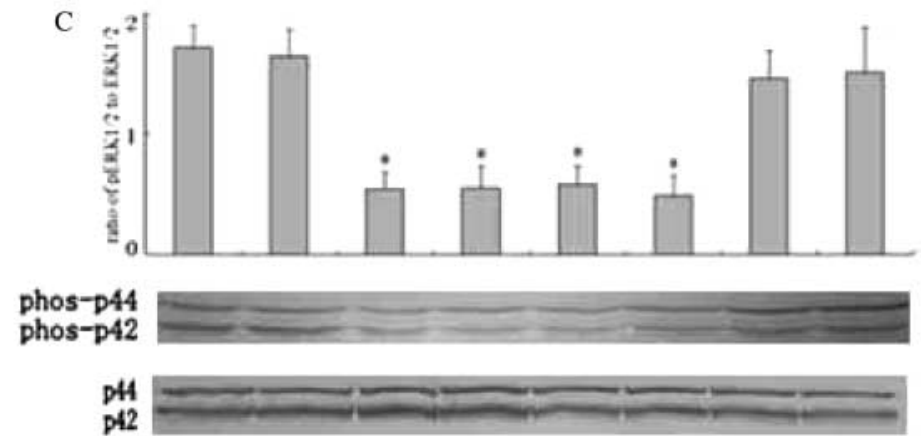

$\begin{array}{lcccccccc}\text { E2 (M) } & 10^{-9} & 10^{-10} & 10^{-9} & 10^{-10} & 10^{-9} & 10^{-10} & 10^{-9} & 10^{-10} \\ \text { ICI } 182.780 & - & - & + & + & - & - & - & - \\ \text { flutamide } & - & - & - & - & - & - & + & + \\ \text { U0126 } & - & - & - & - & + & + & - & -\end{array}$

Figure 6 Effect of DHEA on activation of MAPK signal pathway in OBs. The primary OBs were starved in MEM (serum-free medium) for $24 \mathrm{~h}$, pretreated with solvent, $1 \mu \mathrm{M}$ $\mathrm{ICl} 182780,10 \mu \mathrm{M}$ flutamide, or $100 \mu \mathrm{M}$ U0126 for $25 \mathrm{~min}$, and then treated with DHEA $\left(10^{-7}-10^{-8} \mathrm{M}\right)(\mathrm{A}, \mathrm{B})$ or E2 $\left(10^{-9}-10^{-10} \mathrm{M}\right)(\mathrm{A}, \mathrm{C})$ for $10 \mathrm{~min}$. Western blot analysis was performed to analyze ERK1/2 phosphorylation. Data were presented as a ratio of phosphor-ERK1/2 to total ERK $1 / 2$ (mean \pm S.E.M.; $n=5$ ). ${ }^{*} P<0.01$ compared with the control. 
Thus, some scholars have proposed treating PMO with DHEA (Lamberts et al. 1997). Some experimental and clinical evidence suggests that DHEA plays an important role in the regulation of bone metabolism, for example, Nozaki et al. (2004) reported that the adrenal sex steroids and their derivatives, such as DHEA, might affect bone resorption to some extent in oophorectomized women. DHEA as an additional factor modulating BMD in postmenopausal women (Labrie et al. 1997) emphasizes the need for more information concerning the potential clinical benefit of DHEA for the treatment of PMO (Casson \& Buster 1995, Lamberts et al. 1997). However, both the molecular and biochemical mechanisms by which DHEA exerts its effect on bone metabolism remain shrouded in mystery. Our finding indicates that DHEA has multiple effects on bone metabolism, especially OBs.

\section{DHEA improves the bone tissue morphometry}

After surgical or natural menopause, estrogen deficiency facilitates bone resorption. The bone resorption augmentation promotes bone formation by feedback. Therefore, after estrogen exhaustion, bone turnover increased, but bone resorption exceeds bone formation, which leads to a decrease in bone mass. The bone tissue morphometry analysis of the ovariectomized mice showed that the cancellous (BV/TV) from the OVX mice was significantly lower than that of the shamoperated mice. The OVX mice treated with DHEA had significantly increased $\mathrm{BV} / \mathrm{TV}$ compared with that of the OVX mice given by solvent, which suggests that DHEA can improve the bone tissue morphometry of the PMO model. Furthermore, we isolated OB from calvariae of neonatal $B A L B / c$ littermates by enzymatic digestion and then treated OB with DHEA; the ultrastructure of the OBs was evaluated by TEM. The results indicate an augmentation of the ER area and increase in mitochondrial density in $\mathrm{OB}$ after DHEA administration; these changes are consistent with the cells involved in anabolic metabolism. Therefore, we propose that DHEA increased the anabolic metabolismrelated organelle content in OBs significantly, thus improving the bone milieu. The changes in bone tissue morphometry by DHEA may improve mechanical strength in bone, but this is still untested, which has considerable clinical significance in the prevention and treatment of PMO.

\section{DHEA promotes proliferation and inhibits apoptosis of OB through MAPK signaling pathway independent of either ARs or ERs}

The number of OBs in bone tissue is dependent not only on their proliferation but also on their apoptosis.
The balance between proliferation and apoptosis affects the pool of OBs available to maintain bone homeostasis. The recent observations have demonstrated that regulation of $\mathrm{OB}$ lifespan is critical for the maintenance of the skeleton. The decrease of apoptosis and increase of proliferation in OBs is significantly related to the number of $\mathrm{OBs}$, bone formation rate, and BMD (Manolagas 1999).

In various murine and rat models, the effects of some agents on $\mathrm{OB}$ proliferation have been described. These studies have, however, been mainly performed in OVX animals that were supplemented with $\mathrm{E} 2$ and are limited to a few reports. In sexually immature rats, OVX caused an increase in cell number and PCNA protein expression compared with sham group; in contrast to OVX, E2 supplementation caused a reduced number of PCNA-positive cells (not significant; Tajima et al. 1998, van der Eerden et al. 2002). Likewise, our results in the present study indicate that PCNA expression in OBs from the OVX mice increases significantly.

Estrogen is believed to play an important role in the regulation of bone remodeling. It is reported that administration of estrogen into OVX rats not only inhibited bone resorption but also stimulated bone formation (Chow et al. 1992). In contrast, it is shown that administration of estrogen into OVX rats inhibits the accelerated bone formation induced by OVX (Yokose et al. 1996). Similarly, we found no difference in the expression of PCNA in OBs between OVX mice and OVX mice treated with E2. This suggests that the effects of E2 on bone metabolism cannot be explained by a direct effect of E2, but it may be a secondary effect on OB proliferation. We also found that PCNA expression of $\mathrm{OB}$ after DHEA administration increased significantly compared with the OVX group. The findings show that DHEA can promote OB proliferation by a direct effect.

The DNA content analysis showed that DHEA increased the S-phase and $\mathrm{G}_{2} / \mathrm{M}$ phase, decreased the $\mathrm{G}_{0} / \mathrm{G}_{1}$ phase of $\mathrm{OB}$ cell cycle, and increased PI significantly, while E2 had no effect on PI of OBs compared with the control. The results of apoptosis analysis showed that DHEA could inhibit the serum deprivation-induced early apoptosis of the primary murine OBs in a dose-dependent manner. Normal circulating levels of free $\mathrm{E} 2$ in mice have been estimated to range between 40 and $80 \mathrm{pg} / \mathrm{ml}$ (Edwards et al. 1992, Nelson et al. 1992, Walmer et al. 1992, Bi et al. 2001, Fata et al. 2001). Normal plasma concentration of DHEA is $0 \cdot 001-0 \cdot 03 \mu \mathrm{mol} / \mathrm{l}$. Our investigation confirmed that $10^{-9}-10^{-6} \mathrm{~mol} / 1$ DHEA were capable of decreasing the apoptosis cell population significantly, and the optimal concentration is $10^{-8}-10^{-7} \mathrm{~mol} / 1$, which is higher than the normal plasma concentration. It means high plasma level of DHEA may be beneficial to PMO. 
Although $10^{-9}-10^{-10} \mathrm{~mol} / \mathrm{l} \mathrm{E} 2$ also could inhibit the serum deprivation-induced early apoptosis of the primary murine OBs, the anti-apoptosis effect of $10^{-7}-10^{-8} \mathrm{~mol} / \mathrm{l}$ DHEA is stronger than that of $10^{-9}-10^{-10} \mathrm{~mol} / 1 \mathrm{E} 2$ in OBs.

The results above indicate that DHEA can effectively improve cell cycle, promote proliferation, and inhibit apoptosis of OBs, thus increasing the amount of OBs, which is for potent evidence for clinical application of DHEA in the prevention and treatment of PMO. Our results also showed that $\mathrm{E} 2$ could inhibit $\mathrm{OB}$ apoptosis too, but E2 treatment could not improve OB cell cycle and has no effect on PI of OB. Therefore, our investigation excluded the possibility of DHEA conversion to its downstream metabolic product (E2) and indicated a direct effect on OBs.

From invertebrates to humans, the ERK MAP kinase signaling plays a central role in cell proliferation and apoptosis (Sudoh et al. 2001, Chang et al. 2003). The gonadal hormone through classic ER or AR activates ERK to affect proliferation and apoptosis (Chambliss et al. 2002, Manolagas et al. 2002). To determine whether the effects of DHEA on proliferation, apoptosis, and ERK phosphorylation of OBs is via $\mathrm{ER} \alpha, \mathrm{ER} \beta$, or AR, we used ICI 182780 (ICI) as an ER antagonist, FLUT as an AR antagonist, and U0126 as an inhibitor of MAPK activity and examined whether these agents could block the above-mentioned effects of DHEA. It was shown that $10^{-7}-10^{-8} \mathrm{M}$ DHEA and $10^{-9}-10^{-10}$ M E2 could induce ERK phosphorylation in OBs; ICI 182780 or flutamide could not block efficiently the above-mentioned effects of DHEA, which suggests that modulation of OBs on DHEA is an ER- and AR-independent mechanism, while U0126 could block the above-mentioned effects of DHEA, which means that the effects of DHEA on OBs involve on MAPK signal pathway.

Specific intracellular DHEA-binding sites have been characterized in mouse and human $\mathrm{T}$ lymphocytes (Meikle et al. 1992, Okabe et al. 1995), mouse B16 melanoma cells (Kawai et al. 1995), human vascular smooth muscle (Williams et al. 2002), and rat liver (Kalimi \& Regelson 1988). However, to date, no known cellular DHEA receptor has been isolated or characterized. There is increasing evidence of rapid, plasma membrane-dependent actions of other steroid hormones such as E2 (Caulin-Glaser et al. 1997, LantinHermoso et al. 1997, Shaul 1999), glucocorticoid (Qiu et al. 1998), testosterone (Benten et al. 1997, 1999), growth hormone (GH; Gu et al. 2001), and insulinlike growth factor-I (Cheng et al. 2001, Pouyssegur \& Lenormand 2003) in various cell types. These effects of steroids are mediated by specific plasma membrane receptors; ligand binding to these receptors activates intracellular signaling which modulates specific cellular processes. Liu \& Dillon (2002) have reported that the
DHEA receptors may be expressed on endothelial cell plasma membranes and are coupled to eNOS activity through Gai2 and Gai3. These novel findings should allow us to isolate the putative receptor and reevaluate the physiological role of DHEA. It is important to determine whether the cell surface-initiated actions of DHEA exist in OBs. The direct effects of DHEA on OBs raise the possibility of developing non-metabolized DHEA receptor ligands to evaluate their effects on OBs. Our results support the presumption about plasma membrane-initiated, non-genomic activity of DHEA. This property has been demonstrated for many other steroids.

Rodents normally have much less DHEA than humans. In fact, humans, along with the other primates, are unique among animal species in having adrenals that secrete large amounts of DHEA and especially DHEA-S. Moreover, plasma DHEA-S levels in adult men and women are 100-500 times higher than those of testosterone and 1000-10 000 times higher than those of E2. Therefore, the situation may be very different between human and mice.

In conclusion, there is a bone remodeling imbalance in the ovariectomized mice. DHEA treatment significantly improved the bone tissue morphometry and increased the anabolic metabolism-related organelles contents in OBs; DHEA promotes proliferation and inhibits apoptosis of OBs by a mechanism independent of either AR or ER, suggesting that it may exert its effects via a DHEA-specific receptor directly, and not by way of conversion to androgens or estrogens, which involve phospho-pERK1/2. DHEA might be useful as a novel strategy for the treatment of the metabolism disease, especially PMO.

\section{Acknowledgements}

This work is supported by the National Key Research Program of China 2006CB0F1009 (to D-J Li), Shanghai Foundations of Science and Technology No. 004019061 (to D-J Li), Program for Outstanding Medical Academic Leader (to D-J Li), National Natural Science Foundation of China No. 30472259 (to W-J Wang), the Youth Foundation of Shanghai Hygiene Bureau No. 044Y06 (to Y-D Wang), and the Traditional Chinese Medicine Foundation of Shanghai Public Health Bureau No. 2004L020A (to W-J Wang). The authors declare that there is no conflict of interest that would prejudice the impartiality of this scientific work.

\section{References}

Araghi-Niknam M, Ardestani SK, Molitor M, Inserra P, Eskelson CD \& Watson RR 1998 Dehydroepiandrosterone (DHEA) sulfate prevents 
reduction in tissue vitamin $\mathrm{E}$ and increased lipid peroxidation due to murine retrovirus infection of aged mice. Proceedings of the Society for Experimental Biology and Medicine 218 210-217.

Bates GW Jr, Egerman RS, Umstot ES, Buster JE \& Casson PR 1995 Dehydroepiandrosterone attenuates study-induced declines in insulin sensitivity in postmenopausal women. Annals of the New York Academy of Sciences 774 291-293.

Ben-Nathan D, Padgett DA \& Loria RM 1999 Androstenediol and dehydroepiandrosterone protect mice against lethal bacterial infections and lipopolysaccharide toxicity. Journal of Medical Microbiology 48 425-431.

Benten WP, Lieberherr M, Sekeris CE \& Wunderlich F 1997 Testosterone induces $\mathrm{Ca}^{2+}$ influx via non-genomic surface receptors in activated T cells. FEBS Letters 407 211-214.

Benten WP, Lieberherr M, Giese G, Wrehlke C, Stamm O, Sekeris CE, Mossmann H \& Wunderlich F 1999 Functional testosterone receptors in plasma membranes of T cells. FASEB Journal 13 123-133.

Bi R, Foy MR, Vouimba RM, Thompson RF \& Baudry M 2001 Cyclic changes in estradiol regulate synaptic plasticity through the MAP kinase pathway. PNAS 98 13391-13395.

Casson PR \& Buster JE 1995 DHEA administration to humans: panacea or palaver? Seminars in Reproductive Endocrinology 13 247-256.

Caulin-Glaser T, Garcia-Cardena G, Sarrel P, Sessa WC \& Bender JR $199717 \beta$-estradiol regulation of human endothelial cell basal nitric oxide release, independent of cytosolic $\mathrm{Ca}^{2+}$ mobilization. Circulation Research 81 885-892.

Chambliss KL, Yuhanna IS, Anderson RG, Mendelsohn ME \& Shaul PW 2002 ERbeta has nongenomic action in caveolae. Molecular Endocrinology 16 938-946.

Chang F, Steelman LS, Lee JT, Shelton JG, Navolanic PM, Blalock WL, Franklin RA \& McCubrey JA 2003 Signal transduction mediated by the Ras/Raf/MEK/ERK pathway from cytokine receptors to transcription factors: potential targeting for therapeutic intervention. Leukemia 17 1263-1293.

Cheng HL, Steinway ML, Xin X \& Feldman EL 2001 Insulin-like growth factor-I and Bcl-X(L) inhibit c-jun N-terminal kinase activation and rescue Schwann cells from apoptosis. Journal of Neurochemistry 76 935-943.

Chow J, Tobias H, Colston KW \& Chambers TJ 1992 Estrogen maintains trabecular bone volume in rats not only by suppression of bone resorption but also by stimulation of bone formation. Journal of Clinical Investigation 89 74-78.

Edwards MW, Bain SD, Bailey MC, Lantry MM \& Howard GA 1992 $17 \beta$-estradiol stimulation of endosteal bone formation in the ovariectomized mouse: an animal model for the evaluation of bonetargeted estrogens. Bone 13 29-34.

van der Eerden BC, Emons J, Ahmed S, van Essen HW, Lowik CW, Wit JM \& Karperien M 2002 Evidence for genomic and nongenomic actions of estrogen in growth plate regulation in female and male rats at the onset of sexual maturation. Journal of Endocrinology 175 277-288.

Elefteriou F, Ahn JD, Takeda S, Starbuck M, Yang X, Liu X, Kondo H, Richards WG, Bannon TW \& Noda M 2005 Leptin regulation of bone resorption by the sympathetic nervous system and CART. Nature 434 514-520.

Enserink M 2002 Women's health. The vanishing promises of hormone replacement. Science 297 325-326.

Fata JE, Chaudhary V \& Khokha R 2001 Cellular turnover in the mammary gland is correlated with systemic levels of progesterone and not 17beta estradiol during the estrous cycle. Biology of Reproduction 65 680-688.

Fitzpatrick JL, Mize AL, Wade CB, Harris JA, Shapiro RA \& Dorsa DM 2002 Estrogen-mediated neuroprotection against beta-amyloid toxicity requires expression of estrogen receptor alpha or beta and activation of the MAPK pathway. Journal of Neurochemistry 82 674-682.
Flood JF \& Roberts E 1988 Dehydroepiandrosterone sulfate improves memory in aging mice. Brain Research 448 178-181.

Flynn MA, Weaver-Osterholtz D, Sharpe-Timms KL, Allen S \& Krause G 1999 Dehydroepiandrosterone replacement in aging humans. Journal of Clinical Endocrinology and Metabolism 84 1527-1533.

Gordon GB, Bush DE \& Weisman HF 1988 Reduction of atherosclerosis by administration of dehydroepiandrosterone. Journal of Clinical Investigation 712720.

Granchi D, Ciapetti G, Amato I, Pagani S, Cenni E, Savarino L, Avnet S, Peris JL, Pellacani A, Baldini N et al. 2004 The influence of alumina and ultra-high molecular weight polyethylene particles on osteoblast-osteoclast cooperation. Biomaterials 25 4037-4045.

Gu Y, Zou Y, Aikawa R, Hayashi D, Kudoh S, Yamauchi T, Uozumi H, Zhu W, Kadowaki T, Yazaki Y et al. 2001 Growth hormone signalling and apoptosis in neonatal rat cardiomyocytes. Molecular and Cellular Biochemistry 223 35-46.

Hakkinen K \& Pakarinen A 1993 Muscle strength and serum testosterone, cortisol and SHBG concentration in middle-aged and elderly men and women. Acta Physiologica Scandinavica 148 199-207.

Haning RV Jr, Carlson IH, Flood CA, Hackett RJ \& Longcope C $1991 a$ Metabolism of dehydroepiandrosterone sulfate (DS) in normal women and women with high DS concentrations. Journal of Clinical Endocrinology and Metabolism 73 1210-1215.

Haning RV Jr, Flood CA, Hackett RJ, Loughlin JS, McClure N \& Longcope C $1991 b$ Metabolic clearance rate of dehydroepiandrosterone sulfate, its metabolism to testosterone, and its intrafollicular metabolism to dehydroepiandrosterone, androstenedione, testosterone, and dihydrotestosterone in vivo. Journal of Clinical Endocrinology and Metabolism 72 1088-1095.

Inoue S, Urano T, Ogawa S, Saito T, Orimo A, Hosoi T, Ouchi Y \& Muramatsu M 1999 Molecular cloning of rat efp: expression and regulation in primary osteoblasts. Biochemical and Biophysical Research Communications 261 412-418.

Itani T, Kanai K, Watanabe J, Ogawa R \& Kanamura S 1992 Quantitative analysis of rough endoplasmic reticulum in chondrocytes of articular and tracheal cartilage of rabbits following the systemic administration of hydrocortisone. Journal of Anatomy 181 357-363.

Jiang S, Lee J, Zhang Z, Inserra P, Sokoff D \& Watson RR 1998 Dehydroepiandrosterone (DHEA) reduces immune dysfunction in very old mice as well as synergizing with antioxidant supplements for immune restoration in old retrovirus-infected mice. Journal of Nutritional Biochemistry 9 362-369.

Kalimi M \& Regelson W 1988 Physicochemical characterization of $[3 \mathrm{H}]$ DHEA binding in rat liver. Biochemical and Biophysical Research Communications 156 22-29.

Kawai S, Yahata N, Nishida S, Nagai K \& Mizushima Y 1995 Dehydroepiandrosterone inhibits B16 mouse melanoma cell growth by induction of differentiation. Anticancer Research $\mathbf{1 5}$ 427-431.

Kostenuik PJ, Bolon B, Morony S, Daris M, Geng Z, Carter C \& Sheng J 2004 Gene therapy with human recombinant osteoprotegerin reverses established osteopenia in ovariectomized mice. Bone 34 656-664.

Kostka T, Arsac LM, Patricot MC, Berthouze SE, Lacour JR \& Bonnefoy M 2000 Leg extensor power and dehydroepiandrosterone sulfate, insulin-like growth factor-I and testosterone in healthy active elderly people. European Journal of Applied Physiology 82 83-90.

Labrie F, Diamond P, Cusan L, Gomez JL, Belanger A \& Candas B 1997 Effect of 12-month dehydroepiandrosterone replacement therapy on bone, vagina, and endometrium in postmenopausal women. Journal of Clinical Endocrinology and Metabolism 82 3498-3505.

Lamberts SW, van den Beld AW \& van der Lely AJ 1997 The endocrinology of aging. Science 278 419-424. 
Lantin-Hermoso RL, Rosenfeld CR, Yuhanna IS, German Z, Chen Z \& Shaul PW 1997 Estrogen acutely stimulates nitric oxide synthase activity in fetal pulmonary artery endothelium. American Journal of Physiology 273.

Liu D \& Dillon JS 2002 Dehydroepiandrosterone activates endothelial cell nitric-oxide synthase by a specific plasma membrane receptor coupled to Galpha(i2,3). Journal of Biological Chemistry 277 21379-21388.

Manolagas SC 1999 Cell number versus cell vigor - what really matters to a regenerating skeleton? Endocrinology $1404377-4381$.

Manolagas SC, Kousteni S \& Jilka RL 2002 Sex steroids and bone. Recent Progress in Hormone Research 57 385-409.

McLachlan JA, Serkin CD \& Bakouche O 1996 Dehydroepiandrosterone modulation of lipopolysaccharide-stimulated monocyte cytotoxicity. Journal of Immunology 156 328-335.

Mei Y, Gawai KR, Nie Z, Ramkumar V \& Helfert RH 1999 Age-related reductions in the activities of antioxidant enzymes in the rat inferior colliculus. Hearing Research 135 169-180.

Meikle AW, Dorchuck RW, Araneo BA, Stringham JD, Evans TG, Spruance SL \& Daynes RA 1992 The presence of a dehydroepiandrosterone-specific receptor binding complex in murine T cells. Journal of Steroid Biochemistry and Molecular Biology 42 293-304.

Miller KK 2001 Androgen deficiency in women. Journal of Clinical Endocrinology and Metabolism 86 2395-2401.

Morony S, Capparelli C, Sarosi I, Lacey DL, Dunstan CR \& Kostenuik PJ 2001 Osteoprotegerin inhibits osteolysis and decreases skeletal tumor burden in syngeneic and nude mouse models of experimental bone metastasis. Cancer Research 61 4432-4436.

Nelson JF, Felicio LS, Osterburg HH \& Finch CE 1992 Differential contributions of ovarian and extraovarian factors to age-related reductions in plasma estradiol and progesterone during the estrous cycle of C57BL/6J mice. Endocrinology 130 805-810.

Nozaki M, Hashimoto K \& Nakano H 2004 Relationship between bone resorption and adrenal sex steroids and their derivatives in oophorectomized women. Fertility and Sterility 82 1556-1560.

Nyce JW, Magee PN, Hard GC \& Schwartz AG 1984 Inhibition of 1,2dimethylhydrazine-induced colon tumorigenesis in $\mathrm{Balb} / \mathrm{c}$ mice by dehydroepiandrosterone. Carcinogenesis 5 57-62.

Okabe T, Haji M, Takayanagi R, Adachi M, Imasaki K, Kurimoto F, Watanabe T \& Nawata H 1995 Up-regulation of high-affinity dehydroepiandrosterone binding activity by dehydroepiandrosterone in activated human T lymphocytes. Journal of Clinical Endocrinology and Metabolism 80 2993-2996.

Pouyssegur J \& Lenormand P 2003 Fidelity and spatio-temporal control in MAP kinase (ERKs) signalling. European Journal of Biochemistry 270 3291-3299.

Qiu J, Lou L, Huang X, Lou S, Pei G \& Chen J 1998 Nongenomic mechanisms of glucocorticoid inhibition of nicotine-induced calcium influx in PC12 cells: involvement of protein kinase C. Endocrinology 139 5103-5108.

Rho J, Takami M \& Choi Y 2004 Osteoimmunology: interactions of the immune and skeletal systems. Molecules and Cells 17 1-9.

Robey PG \& Termine JD 1985 Human bone cells in vitro. Calcified Tissue International 37 453-460.

Schecroun N \& Delloye Ch 2004 In vitro growth and osteoblastic differentiation of human bone marrow stromal cells supported by autologous plasma. Bone 35 517-524.
Schwartz AG \& Pashko LL 1993 Cancer chemoprevention with the adrenocortical steroid dehydroepiandrosterone and structural analogs. Journal of Cellular Biochemistry 17G 73-79.

Schwartz AG, Whitecomb JM, Nyce JW, Lewbart ML \& Pashko LL 1988 Dehydroepiandrosterone and structural analogs: a new class of cancer chemopreventive agents. Advances in Cancer Research $\mathbf{5 1}$ 391-424.

Shaul PW 1999 Rapid activation of endothelial nitric oxide synthase by estrogen. Steroids 64 28-34.

Short KR \& Nair KS 1999 Mechanisms of sarcopenia of aging. Journal of Endocrinological Investigation 22 95-105.

Simoncini T, Mannella P, Fornari L, Varone G, Caruso A \& Genazzani AR 2003 Dehydroepiandrosterone modulates endothelial nitric oxide synthesis via direct genomic and nongenomic mechanisms. Endocrinology 144 3449-3455.

Sudoh N, Toba K, Akishita M, Ako J, Hashimoto M, Iijima K, Kim S, Liang YQ, Ohike Y, Watanabe T et al. 2001 Estrogen prevents oxidative stress-induced endothelial cell apoptosis in rats. Circulation 103 724-729.

Tajima Y, Yokose S, Kawasaki M \& Takuma T 1998 Ovariectomy causes cell proliferation and matrix synthesis in the growth plate cartilage of the adult rat. Histochemical Journal 30 467-472.

Thomsen JS, Ebbesen EN \& Mosekilde LA 2000 A new method of comprehensive static histomorphometry applied on human lumbar vertebral cancellous bone. Bone 27 129-138.

Walmer DK, Wrona MA, Hughes CL \& Nelson KG 1992 Lactoferrin expression in the mouse reproductive tract during the natural estrous cycle: correlation with circulating estradiol and progesterone. Endocrinology 131 1458-1466.

Williams MR, Ling S, Dawood T, Hashimura K, Dai A, Li H, Liu JP, Funder JW, Sudhir K \& Komesaroff PA 2002 Dehydroepiandrosterone inhibits human vascular smooth muscle cell proliferation independent of ARs and ERs. Journal of Clinical Endocrinology and Metabolism 87 176-181.

Yen SSC, Morales AJ \& Khorram O 1995 Replacement of DHEA in aging men and women. Annals of the New York Academy of Sciences 774 128-142.

Yokose S, Ishizuya T, Ikeda T, Nakamura T, Tsurukami H, Kawasaki K, Suda T, Yoshiki S \& Yamaguchi A 1996 An estrogen deficiency caused by ovariectomy increases plasma levels of systemic factors that stimulate proliferation and differentiation of osteoblasts in rats. Endocrinology 137 469-478.

Zhang Z, Araghi-Niknam M, Liang B, Inserra P, Ardestani SK, Jiang S, Chow S \& Watson RR 1999 Prevention of immune dysfunction and vitamin $\mathrm{E}$ loss by dehydroepiandrosterone and melatonin supplementation during murine retrovirus infection. Immunology 96 291-297.

Zhioua A, Hamdoun M, Chappard D, Basle MF \& Jaafoura MH 1994 Bone histomorphometry in 50 normal Tunisian subjects. Clinical Rheumatology 13 581-585.

Received in final form 15 January 2007

Accepted 24 January 2007

Made available online as an Accepted Preprint 25 January 2007 